\title{
Family and parenting characteristics associated with marijuana use by Chilean adolescents
}

\author{
This article was published in the following Dove Press journal: \\ Substance Abuse and Rehabilitation \\ 3 March 20II \\ Number of times this article has been viewed
}

\section{Cristina B Bares' Jorge Delva ${ }^{2}$ \\ Andrew Grogan-Kaylor ${ }^{2}$ Fernando Andrade ${ }^{3}$ \\ 'Curtis Research and Training Center, School of Social Work, ${ }^{2}$ School of Social Work, ${ }^{3}$ School of Education, University of Michigan, Ann Arbor, MI, USA}

Objective: Family involvement and several characteristics of parenting have been suggested to be protective factors for adolescent substance use. Some parenting behaviors may have stronger relationships with adolescent behavior while others may have associations with undesirable behavior among youth. Although it is generally acknowledged that families play an important role in the lives of Chilean adolescents, scant research exists on how different family and parenting factors may be associated with marijuana use and related problems in this population which has one of the highest rates of drug use in Latin America.

Methods: Using logistic regression and negative binomial regression, we examined whether a large number of family and parenting variables were associated with the possibility of Chilean adolescents ever using marijuana, and with marijuana-related problems. Analyses controlled for a number of demographic and peer-related variables.

Results: Controlling for other parenting and family variables, adolescent reports of parental marijuana use showed a significant and positive association with adolescent marijuana use. The multivariate models also revealed that harsh parenting by fathers was the only family variable associated with the number of marijuana-related problems youth experienced.

Conclusion: Of all the family and parenting variables studied, perceptions of parental use of marijuana and harsh parenting by fathers were predictors for marijuana use, and the experience of marijuana-related problems. Prevention interventions need to continue emphasizing the critical socializing role that parental behavior plays in their children's development and potential use of marijuana.

Keywords: parenting, families, adolescent, drugs, marijuana use, Chile

\section{Introduction}

According to the 2009 United Nations World Drug Report, and studies conducted by the Organization of American States Inter-American Drug Abuse Control Commission and by several Latin American countries, illicit drug use in Latin America during the past 10 to 15 years has been stable or on the rise. ${ }^{1-5}$ Chile, a developing country with a strong market-driven economy and a respectable democratic history, apart from the Pinochet dictatorship era, appears to be experiencing a rise in illicit drug consumption. In a recent study of nine South American countries, Chile ranks highest in marijuana use. ${ }^{2}$

It has been well documented that multiple social contexts influence adolescent behavior and adolescent decisions to begin using harmful substances. ${ }^{6,7}$ Yet, as adolescents begin to move into new social environments and away from the family, many of their behaviors continue to be constrained and shaped by their family environment.
Correspondence: Cristina B Bares Postdoctoral Research Fellow, Curtis Research and Training Center, School of Social Work, University of Michigan, Ann Arbor, Ml 48109, USA Tel +l (734) 763-5959

Email cbb@umich.edu 
Despite the generally acknowledged central role that Latino families play in their children's development, adolescent drug use in Latin America continues to rise. Are Chilean families and parents not having the same protective influences on their children as they may once have had?

Studies that examine the association between family and parenting characteristics and their children's drug use in Chile are rare. ${ }^{8}$ Current existing literature on Chilean families indicates that adolescents who perceive their families as dysfunctional are at greater risk of using substances including marijuana., ${ }^{9,10}$ Our awareness of the important influence on adolescent development of a number of other family characteristics led us to the central aim of this paper, that is, to examine a variety of family factors among adolescents in a country with high rates of drug use, allowing for a simultaneous examination of the familial processes that influence adolescent decisions to use marijuana, and how these same processes influence the type of marijuana-related problems that Chilean adolescents experience. This paper examines multiple aspects of the family social context and their effect on adolescent marijuana use among a sample of community-dwelling Chilean adolescents. We discuss each of these aspects next.

\section{Family involvement}

Family involvement has been defined as the extent to which parents are interested in, knowleageable about, and willing to participate in the lives of their children. Various studies have found that adolescents who report that they are involved less with their families are more likely to use marijuana. ${ }^{11}$ Adlaf and colleagues operationalized family involvement as the time that adolescents spend with their families and found that time spent together was inversely related to adolescent substance use. ${ }^{12}$ In addition, low levels of family involvement have been linked to a number of problem behaviors during adolescence including marijuana use. ${ }^{13-15}$

\section{Parental monitoring}

It has been well established that parents who think it is important to know where their children are when not at home, and who spend time with their children, are less likely to have adolescents who use substances. ${ }^{16,17}$ Various studies support the role that parental monitoring plays in attenuating adolescent delinquency and drug use. ${ }^{18-21}$ The protective effect of parental monitoring has been found to extend even through to the college years. ${ }^{22}$ Several researchers have shown that more parental monitoring reduces the likelihood that Latino adolescents use marijuana and that the effect of monitoring is long lasting in this population..$^{23,24}$ One way the protective role of parental monitoring works is by reducing the opportunities that adolescents have to try marijuana in their lifetime ${ }^{25}$ and by reducing the number of marijuana-related social problems that adolescents experience. ${ }^{26}$

\section{Parenting practices}

Research has also shown that warm parenting practices have direct and indirect effects on adolescent substance use. ${ }^{27}$ An increase in levels of parental warmth has been found to decrease adolescent alcohol use and, indirectly, to act through the parent-child relationship to decrease substance use. ${ }^{28}$ Conversely, neglectful parenting has been found to contribute significantly to adolescent substance use. ${ }^{29}$ In addition, negative interactions between family members, characterized by harsh discipline and conflict, have been shown to be related to marijuana-related problems. ${ }^{30}$

\section{Parental control}

The literature examining substance use among adolescents suggests that having more controlling parents leads to more adolescent substance use. ${ }^{31} \mathrm{~A}$ distinction has been made between different types of parental control. When coercive control is defined to include actions such as parents taking away privileges, parents yelling at the adolescent, or slapping them, studies show that greater amounts of coercive control are associated with more problem behaviors. ${ }^{32}$ However, in a study examining Latino adolescents in the United States, parental control in the form of, for example, what the adolescent should or should not wear, the time when the adolescent must be home on weekends, the friends with whom the adolescent spends time, and which television programs the adolescent watched, was associated with decreases in adolescent alcohol use. ${ }^{28}$ Increases in parental control among Latinos are thought to be a traditional and cultural norm that protects against the use of harmful substances and other problem behavior. The influence of parental control on adolescents from Latin America has not been studied, so it is not possible to determine if the above finding is true of all Latino families or if Latino families in the United States exert more control over their adolescents as a way of protecting them from the stressors of being minorities.

\section{Parental substance use}

According to social learning theory, ${ }^{33}$ the strongest predictor of whether adolescents use substances is whether their parents also use substances. ${ }^{34}$ The attitudes and actions of parents both influence the degree to which adolescents 
use substances..$^{35}$ Numerous studies ${ }^{17,36-39}$ provide strong evidence that parental substance use influences the use of substances by children, albeit indirectly. Furthermore, which substances parents use may also influence the type of substance that adolescents may subsequently use. For example, Andrews et al found that adolescents may tend to model their mother's smoking behavior but their father's drinking behavior, suggesting a complex interplay of factors associated with adolescent substance use. ${ }^{35}$

Altogether, several aspects of the family environment in which adolescents develop including the quality of the relationship with their parents and the amount of monitoring received, in addition to whether parents use substances, are all likely to influence adolescent substance use.

\section{Study rationale}

To the best of our knowledge, very few studies of Chilean families exist that simultaneously examine the variety of family and parenting characteristics and behaviors that are likely to have an effect on whether adolescents use marijuana or whether parental use of different drugs is likely to influence adolescent substance use. We conducted a comprehensive literature review of published studies of substance use among youth in Chile. ${ }^{40-46}$ None of these publications included information on families. On the other hand, governmental organizations, including the Organization of American States Inter-American Drug Abuse Control Commission, produce very informative unpublished reports, but the findings are limited to bivariate analyses. To fill this gap in our knowledge, in this paper we present findings using data from the first wave of an ongoing longitudinal study of adolescents in Santiago, Chile, in which 9 family and parenting variables were included in the analyses to examine how they were associated with adolescent marijuana use and marijuana-related problems experiened by Chilean adolescents.

\section{Materials and method Sample and procedures}

This study used data from the first part of a 2-part assessment, scheduled 2 years apart, of adolescents participating in the Santiago Longitudinal Study (SLS), a study of community-dwelling adolescents in low socioeconomic neighborhoods in Santiago, Chile. This study is a collaborative project between US and Chilean institutions with funding from the National Institute on Drug Abuse (NIDA). Participants for this study included a convenience sample of adolescents who, during infancy $(n=1,657)$, had par- ticipated in a study on the effects of iron supplementation. ${ }^{47}$ Participants were healthy infants recruited from health and mental health clinics serving working-class communities in the southern part of the city of Santiago. Subsequently, approximately 1200 of these youth were successfully followed and re-interviewed when they were 10 years old. The sample for the present study comes mainly from these 1200 children and from the initial 1657 who were not interviewed at age 10 .

In all, 1030 adolescents were interviewed in 2008 to 2010. The analytic sample for the current study includes the 898 participants who had provided data on all the variables of interest. A total of 98 (9.5\%) of the participants reported not having a biological father or other father figure to enable them to respond to questions on the quality of the relationship with their fathers and, consequently, were removed from the analyses. An additional 34 (3.3\%) participants were removed from the analyses because they had missing data on the relevant variables. The resulting analytic sample used in this study consisted of 898 adolescents (mean age $=14$, $\mathrm{SD}=1.4,48 \%$ female) of mid-to-low socioeconomic status with complete data.

Adolescent participants completed a 2-hour intervieweradministered questionnaire with standardized measures, which were pilot-tested with 30 adolescents before the present study was conducted. Adolescents were asked to indicate if they had any difficulties understanding the questions and response categories. Simultaneously, the interviewers paid attention to any items the youth would have difficulty understanding. Overall, only a few items were unclear and these were modified by making minor adjustments to the terms. We believe the changes were minor because extensive time (about a year) was spent translating, back translating, and checking the language, semantic, and conceptual equivalence of the items by the research team.

Topics assessed ranged from assessing the adolescents' relationship with parents, perceptions of self, perceptions of parental use of drugs and perceptions of family characteristics, behavior, and substance use, among others. Interviews were conducted in Spanish in a private office at the University of Chile by Chilean psychologists trained in the administration of standardized instruments. Adolescent assent and parental consent were obtained by the interviewers before commencing the interviews. The study received Human Subjects approval from the institutional review boards of the corresponding universities. Upon completion of the interview, adolescent participants received a gift of movie tickets in recognition of their participation. 


\section{Measures}

\section{Dependent measures}

The study's dependent variables were adolescent self-reports of lifetime use of marijuana and self-reported problems that resulted from using this substance. Questions were taken from standard questions utilized in national school surveys conducted in Chile, questions that mirror those asked in similar US surveys such as Monitoring the Future ${ }^{48}$ and surveys in other Latin American countries.

\section{Lifetime marijuana use}

Lifetime use was assesed with a single question that asked if the participant had ever used marijuana. Response options were " $1=$ Yes" and " $0=N o "$.

\section{Marijuana-related problems}

Problems related to the consumption of marijuana were assessed by asking participants who had indicated that they had used marijuana, to check from a list of 14 problems which problems they may have experienced. These questions were taken from those used by the US Monitoring the Future Study ${ }^{48}$ and Chilean school-based surveys. The stem question read "Has your use of marijuana ever caused any of the following problems for you?" Example items were "Hurt your relationship with your parents", "Hurt your relationships with your friends", "Caused you to be less stable emotionally", and "Caused you to behave in ways that you later regretted". Response options were 1 for "Yes" and 0 for "No". A composite score of marijuana-related problems was created with youth scores ranging from 0 to 13 with higher scores representing more problems (Cronbach's alpha $=0.84$ ).

\section{Independent measures}

The independent variables were the adolescents' perception of parental monitoring, family involvement, adolescents' reports regarding their parents' warmth (for both mothers and fathers), their parents' level of harsh parenting (for both mothers and fathers), reports of parental control, as well as parental cigarette smoking, parental alcohol use, and parental marijuana use.

\section{Family involvement}

Adolescents' self-report of their family involvement was assessed through 5 items from the Child Health and Illness Profile-Adolescent Edition which has previously been validated with a Spanish sample of adolescents. ${ }^{49-51}$ The stem question "Thinking about your family, about how many days in the past 4 weeks did your parents or other adults in your family ..." was followed by items such as "spend time with you doing something fun", "eats meals with you", and "talk with you or listens to your opinions and ideas". The response categories were " $1=$ No days", " $2=1$ to 3 days", " $3=4$ to 6 days", " $4=7$ to 14 days", and " $5=15$ to 28 days". Higher scores indicate greater levels of family involvement $($ Cronbach's alpha $=0.73)$.

\section{Parental monitoring}

Adolescents' self-reports of how much parental monitoring they receive was assessed by 10 questions used in a National Institute of Child Health and Human Development (NICHHD) Study of Early Child Care and Youth Development. ${ }^{52}$ Example items included "If your mom/dad or guardian are not home, how often do you leave a note for them about where you are going?" and "How often, before you go out, do you tell your mom/dad or guardian when you will be back." The response categories for these questions were " $1=$ All of the time", " 2 = Most times", " 3 = Sometimes", " $4=$ Hardly ever", and " $5=$ Never". After reverse coding all of the items, a composite score was created by adding the responses to the 10 questions with higher scores representing more parental monitoring $($ Cronbach's alpha $=0.66)$.

\section{Warm parenting practices}

Warm parenting behavior was assessed by 9 questions that assessed caring and loving parenting practices originating from the Iowa Family Interaction Rating Scales..$^{53-55}$ The stem question was "How often does your __ (mother/father) ..." followed by items such as "lets you know that she/he really cares about you", "listens carefully to your point of view". Response options to the 9 items were " $1=$ Never", "2 = Sometimes","3 = Often", and " $4=$ Always". Higher scores on the composite score represent a warmer parenting style. Cronbach's alpha for the warm parenting scale for mother was 0.92 and for the father was 0.93 .

\section{Harsh parenting practices}

The construct of harsh parenting practices was assessed by 8 questions with the same stem question as the warm parenting construct, which also originated from the Iowa Family Interaction Rating Scales. ${ }^{54}$ Example items were "get angry at you", "insult or swear at you" and "boss you around a lot". Response categories were the same ones as for the warm parenting construct. Higher responses on this variable indicate a harsher parenting style. Cronbach's alpha for the harsh parenting scale for mother was 0.80 and for the father was 0.77 . 


\section{Parental control}

Adolescents were asked 8 questions that assessed their degree of autonomy from their parents. ${ }^{56,57}$ The stem question was: "This next set of questions is about how decisions are made in your family. In your family, how do you make most of the decisions about the following topics?" Examples of questions were "How late you can stay up on a school night", "Which friends you can spend time with", and "What you watch on TV or whether you watch TV at all". Response categories were "1 = My parents decide", "2 = My parents decide after discussing it with me", "3 = We decide together", "4 = I decide after discussing it with my parents", and "5 = I decide all by myself". A composite score was created by adding all the responses across the 8 questions. Scores ranged from 8 to 40 with higher scores representing less parental control $($ Cronbach's alpha $=0.69)$.

\section{Perception of caregiver substance use}

Adolescents were asked 5 questions to assess their perception of their parents'/caregiver's substance use. The questions were adapted from the National Survey on Drug Use and Health (NSDUH) supported by the Substance Abuse and Mental Health Services Administration (SAMSHA) in the US and from a national survey by the Consejo Nacional para el Control de Estupefacientes (CONACE) in Chile. The stem question was: "During the past 12 months, do you think your parent or someone who takes care of you has tried any of the following substances? A. cigarettes, B. alcohol, and C. marijuana". Response categories for each of these drugs were on a four-point scale: "4 = Definitely yes", "3 = Probably yes", "2 = Probably no", "1 = Definitely no".

Control variables included adolescent demographics and several peer-related variables. These variables are described next.

\section{Demographics}

Youth age and sex were based on self-report, and family socioeconomic status was based on parent reports. Socioeconomic status (SES) was assessed according to 13 items from the Graffar instrument, ${ }^{58}$ an SES scale that was designed with questions sensitive to SES circumstances in developing countries. Items from this scale include "total number of adults in the same house" "type of job by head of household", "father's education", and "type of sewage accommodations (toilet, black well, open field)". The measure was completed by the parent who brought the youth to the interview site. Higher scores indicate higher SES.

\section{Peer substance use}

To assess the number of adolescent peers who use substances, the portion of the Child Health and Illness Profile that inquires about peers was administered..$^{50,51}$ The corresponding number of peers who used cigarettes, alcohol, and marijuana, was assessed by asking adolescents to indicate the number of their friends who use each of these substances, respectively. In 3 separate questions, participants were asked "How many of your friends do you estimate would" followed by "smoke cigarettes", "drink alcoholic beverages", and "smoke marijuana". Response categories for each of the substances were "1 = None", "2 = A few", "3 = Some", "4 = Most", and "5 = All".

\section{Peer pressure to use substances}

To assess the extent to which adolescents were pressured by their peers to use drugs, the Child Health and Illness Profile was administered. Participants were asked "How much pressure do you feel from your friends and schoolmates to" followed by "smoke cigarettes", "drink alcoholic beverages", and "use marijuana". ${ }^{50}$ Response categories for each drug were "1 = None", "2 = A Little", "3 = Some", and "4 = A Lot".

\section{Analysis}

Logistic regression was utilized to examine variables that might be associated with whether adolescents had used marijuana in their lifetime. Subsequently, for those adolescents who reported marijuana use in their lifetime, we examined whether or not family and parenting characteristics offered any protective effect on the number of marijuana-related problems that adolescents reported. Because of the way responses on marijuana-related problems were counted, as well as the presence of overdispersion in the distribution of this outcome variable, this analysis was conducted with negative binomial regression. All analyses included statistical controls for age, sex, family socioeconomic status, and the peer variables described earlier, and were conducted with Stata 11.1.59

\section{Results \\ Descriptive data}

In this sample, a total of 121 participants $(13.4 \%)$ had used marijuana at some time. All youth who had used marijuana had already consumed alcohol and smoked cigarettes. On average, onset of marijuana use occurred around 15 years of age and $42 \%$ of the users were girls. In the past 30 days, about $64 \%$ had not used marijuana, $22 \%$ had used marijuana on one occasion, 
and $14 \%$ of the sample had used it on more than 2 occasions. When questioned about marijuana-related problems, 42\% of lifetime users reported not having experienced any of the 14 marijuana-related problems, 14\% reported experiencing one marijuana-related problem, another $14 \%$ reported 2 problems, and $32 \%$ reported 3 or more problems. More descriptive information is provided in Table 1.

\section{Lifetime use of marijuana}

Table 2 presents the results of the bivariate and multiple logistic regression analyses examining the association of family and parenting factors with adolescents' lifetime marijuana use. In the bivariate analyses the relationship between adolescent lifetime use of marijuana was examined with each independent variable separately, even though the results are presented together in our tables for the sake of parsimony. Among the family and parenting variables, results of bivariate analyses indicate that family involvement (odds ratio $[\mathrm{OR}]=0.95,95 \%$ confidence interval $[\mathrm{CI}]=0.91-0.98)$, parental monitoring $(\mathrm{OR}=0.91 ; 95 \% \mathrm{CI}=0.88-0.94)$, warm parenting by mother $(\mathrm{OR}=0.95 ; 95 \% \mathrm{CI}=0.93-0.98)$, and warm parenting by father $(\mathrm{OR}=0.95 ; 95 \% \mathrm{CI}=0.93-0.98)$ were each inversely associated with ever use of marijuana

Table I Descriptive characteristics of the sample $(n=898)$

\begin{tabular}{ll}
\hline Variables & $\begin{array}{l}\text { Overall sample } \\
\text { M (SD) or N (\%) }\end{array}$ \\
\hline Demographics & $433(48 \%)$ \\
Female & $14.4(1.4)$ \\
Age (in years) & $32.8(6.7)$ \\
Socioeconomic status (Graffar) & \\
Dependent variables & $121(13.4 \%)$ \\
Lifetime marijuana use & $2.1(2.8)$ \\
Marijuana-related problems & \\
Independent variables & $18.7(4.2)$ \\
Family involvement & $27.6(5.2)$ \\
Parental monitoring & $13.5(3.5)$ \\
Harsh parenting by mom & $12.1(3.4)$ \\
Harsh parenting by dad & $29.0(6.2)$ \\
Warm parenting by mom & $26.5(7.4)$ \\
Warm parenting by dad & $3.3(1.2)$ \\
Parental cigarette use & $3.4(0.9)$ \\
Parental alcohol use & $1.3(0.8)$ \\
Parental marijuana use & $2.6(1.2)$ \\
Number of peers who use cigarettes & $2.4(1.2)$ \\
Number of peers who use alcohol & $1.7(0.9)$ \\
Number of peers who use marijuana & $1.3(0.7)$ \\
Peer pressure to smoke & $1.2(0.6)$ \\
Peer pressure to drink & $1.2(0.6)$ \\
Peer pressure to use marijuana & $30.3(6.1)$ \\
Youth autonomy &
\end{tabular}

Abbreviation: SD, standard deviation. by adolescents. In addition, harsh parenting by mother $(\mathrm{OR}=1.09 ; 95 \% \mathrm{CI}=1.04-1.15)$, by father $(\mathrm{OR}=1.07 ; 95 \%$ $\mathrm{CI}=1.02-1.13)$, certainty of parental alcohol use $(\mathrm{OR}=1.29$; $95 \% \mathrm{CI}=1.02-1.63)$, and marijuana use (OR $=1.71 ; 95 \%$ $\mathrm{CI}=1.42-2.05)$ were each positively associated with adolescents' ever use of marijuana. Among the control variables, age $(\mathrm{OR}=2.35 ; 95 \% \mathrm{CI}=2.02-2.74)$, number of peers who use cigarettes $(\mathrm{OR}=2.80 ; 95 \% \mathrm{CI}=2.28-3.43)$, number of peers who use alcohol $(\mathrm{OR}=2.61 ; 95 \% \mathrm{CI}=2.16-3.15)$, number of peers who use marijuana $(\mathrm{OR}=2.75 ; 95 \%$ $\mathrm{CI}=2.29-3.31)$, peer pressure to use marijuana $(\mathrm{OR}=1.34$; $95 \% \mathrm{CI}=1.05-1.71)$, and youth autonomy $(\mathrm{OR}=1.42 ; 95 \%$ $\mathrm{CI}=1.10-1.19)$ were each positively associated with ever use of marijuana.

Results of the multiple logistic regression analyses, which included all of the family, parenting and control variables simultaneously, showed that greater certainty of parental marijuana use was 1 of 2 family and parenting variables that remained significantly associated with adolescents' ever use of marijuana (adjusted OR [aOR] $=1.40 ; 95 \% \mathrm{CI}=1.08-1.84$ ). Secondly, we found that lack of parental control was found to be associated with an increased probability of ever having used marijuana. However, the loss of statistical significance for some of these variables may be due to the relatively small sample used in this analysis as the odds ratios of several of the parenting and family variables that became nonsignificant in the multivariate models decreased only minimally (see

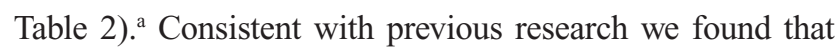
the more adolescents are certain that their parents have used marijuana, the more likely they are also to use the drug. ${ }^{35,60}$ In addition, consistent with the developmental stage of this population we found that less parental control was associated with adolescents' greater likelihood of using marijuana, a finding that has also been previously reported.

In the multivariate analyses, almost the same number of control variables remained significant. Adolescent age $(\mathrm{aOR}=2.08 ; 95 \% \mathrm{CI}=1.70-2.55)$, having more peers who smoke cigarettes $(\mathrm{aOR}=1.78 ; 95 \% \mathrm{CI}=1.32-2.42)$, and having peers who use marijuana $(\mathrm{aOR}=1.90,95 \% \mathrm{CI}=1.48-2.44)$

\footnotetext{
${ }^{a}$ As a specification test of our models, we conducted additional analyses to examine if any one variable was responsible for the loss of significance by the family and parenting variables when in the multivariate models. To do this, we built the multivariate models by adding predictor variables one at a time and examining how the significance levels were changing. Results of these analyses indicate that no single parenting variable was responsible for the loss of significance of the parenting and family variables. Rather, it was the combination of the parenting and family variables and the variable measuring how many peers use marijuana that resulted in the loss of significance.
} 
Table 2 Family and parenting characteristics associated with adolescent report of lifetime marijuana use: results of bivariate and multiple logistic regression analyses $(n=898)$

\begin{tabular}{|c|c|c|c|c|}
\hline & \multicolumn{2}{|c|}{$\begin{array}{l}\text { Bivariate } \\
\text { Odds ratio } 95 \% \mathrm{Cl}\end{array}$} & \multicolumn{2}{|c|}{$\begin{array}{l}\text { Multivariate } \\
\text { Odds ratio } 95 \% \mathrm{Cl}\end{array}$} \\
\hline \multicolumn{5}{|l|}{ Family and parenting variables } \\
\hline Family involvement & 0.95 & $0.9 I, 0.98$ & 1.01 & $0.94,1.08$ \\
\hline Parental monitoring & 0.91 & $0.88,0.94$ & 0.98 & $0.93,1.04$ \\
\hline Harsh parenting by mom & 1.09 & $1.04,1.15$ & 1.04 & $0.96,1.14$ \\
\hline Harsh parenting by dad & 1.07 & $1.02,1.13$ & 1.04 & $0.96,1.12$ \\
\hline Warm parenting by mom & 0.95 & $0.93,0.98$ & 1.01 & $0.96,1.06$ \\
\hline Warm parenting by dad & 0.95 & $0.93,0.98$ & 0.99 & $0.96,1.04$ \\
\hline Parental cigarette use & 1.12 & $0.94,1.33$ & 0.92 & $0.71,1.18$ \\
\hline Parental alcohol use & 1.29 & $1.02,1.63$ & 1.18 & $0.85,1.63$ \\
\hline Parental marijuana use & I.7I & $1.42,2.05$ & 1.40 & I.08, I.84 \\
\hline \multicolumn{5}{|l|}{ Control variables } \\
\hline Age & 2.35 & $2.02,2.74$ & 2.08 & $1.70,2.55$ \\
\hline Gender (ref. = M) & 0.75 & $0.5 \mathrm{I}, \mathrm{I} .09$ & 0.55 & $0.33,0.91$ \\
\hline SES & 1.01 & $0.98,1.04$ & 1.02 & $0.98,1.06$ \\
\hline Number of peers who use cigarettes & 2.80 & $2.28,3.43$ & 1.78 & $1.32,2.42$ \\
\hline Number of peers who use alcohol & 2.61 & $2.16,3.15$ & 0.91 & $0.66,1.24$ \\
\hline Number of peers who use marijuana & 2.75 & $2.29,3.31$ & 1.90 & $1.48,2.44$ \\
\hline Peer pressure to smoke & 1.08 & $0.83,1.40$ & I.II & $0.69,1.78$ \\
\hline Peer pressure to drink & 1.28 & $0.97,1.68$ & 0.69 & $0.39,1.20$ \\
\hline Peer pressure to use marijuana & 1.34 & I.05, I.7 I & 1.22 & $0.76,1.95$ \\
\hline Youth autonomy & 1.42 & $1.10,1.19$ & 1.05 & I.0I, I.I I \\
\hline
\end{tabular}

Note: For ease of interpretation, we have used bold text to highlight statistically significant findings.

Abbreviation: $\mathrm{Cl}$, confidence interval.

were positively associated with adolescent marijuana use. In the multivariate context, girls had lower odds of having ever used marijuana than boys $(\mathrm{aOR}=0.55 ; 95 \% \mathrm{CI}=0.33-0.91)$.

\section{Marijuana-related problems}

Table 3 presents the results of the analyses on the association of family and parenting characteristics, with the number of marijuana-related problems among adolescents who had ever used marijuana. Results of the bivariate analyses indicate that family involvement (rate ratio $[\mathrm{RR}]=0.94$; $95 \% \mathrm{CI}=0.89-0.99)$, parental monitoring $(\mathrm{RR}=0.95 ; 95 \%$ $\mathrm{CI}=0.90-0.99)$, and warm parenting by dad $(\mathrm{RR}=0.96$; $95 \% \mathrm{CI}=0.93-0.99)$ were each inversely associated with the number of marijuana-related problems. The number of peers who use marijuana $(\mathrm{RR}=1.47 ; 95 \% \mathrm{CI}=1.22-1.78)$ and peer pressure to use marijuana $(\mathrm{RR}=1.57 ; 95 \% \mathrm{CI}=1.07-2.30)$ were each found to be positively associated with the number of marijuana-related problems reported by adolescents.

In the multiple logistic regression analyses, the number of marijuana-related problems was significantly and positively associated with harsh parenting by dad (aRR $=1.12 ; 95 \%$ $\mathrm{CI}=1.02-1.23)$. Of the control variables, marijuana-related problems remained positively associated with number of peers who use marijuana $(\mathrm{aRR}=1.89 ; 95 \% \mathrm{CI}=1.45-2.45)$, peer pressure to drink alcohol $(\mathrm{aRR}=1.79 ; 95 \% \mathrm{CI}=1.08-2.99)$ and adolescent autonomy $(\mathrm{aRR}=1.06 ; 95 \% \mathrm{CI}=1.01-1.14)$, but inversely associated with number of peers who use alcohol $(\mathrm{aRR}=0.53 ; 95 \% \mathrm{CI}=0.39-0.75)$.

\section{Discussion}

In this study we set out to explore the contextual socializing forces behind adolescent marijuana use and marijuana-related problems by focusing on how various aspects of parenting behavior, as reported by adolescents, influenced the use of marijuana by Chilean adolescents in a country with one of the highest rates of drug use in Latin America. Consistent with findings from other studies conducted in Latin America we found that about $10 \%$ of the adolescents in this study had tried marijuana at least once in their lifetime, a number that is higher than reported in other Latin American countries. ${ }^{30}$ The study findings on marijuana use provide extensive support for the protective role that family involvement, parental monitoring, and warm parenting exert on Chilean adolescents, as well how harsh parenting and perception of parental substance use negatively influence youth. However, when all family and parenting variables were examined simultaneously, including a number of important controls such peer influences, the only parent variable that was positively associated with whether 
Table 3 Family and parenting characteristics associated with number of marijuana-related problems among current users only: results of bivariate and multiple negative binomial analyses $(n=121)$

\begin{tabular}{|c|c|c|c|c|}
\hline & \multicolumn{2}{|c|}{$\begin{array}{l}\text { Bivariate } \\
\text { Rate ratio } 95 \% \mathrm{Cl}\end{array}$} & \multicolumn{2}{|c|}{$\begin{array}{l}\text { Multivariate } \\
\text { Rate ratio } 95 \% \mathrm{Cl}\end{array}$} \\
\hline \multicolumn{5}{|l|}{ Family and parenting variables } \\
\hline Family involvement & 0.94 & $0.89,0.99$ & 1.01 & $0.95,1.07$ \\
\hline Parental monitoring & 0.95 & $0.90,0.99$ & 1.03 & $0.97,1.09$ \\
\hline Harsh parenting by mom & 1.07 & $1.01,1.13$ & 1.01 & $0.95,1.07$ \\
\hline Harsh parenting by dad & 1.06 & $0.99,1.24$ & 1.12 & $1.02,1.23$ \\
\hline Warm parenting by mom & 0.97 & $0.93,1.01$ & 0.97 & $0.92,1.02$ \\
\hline Warm parenting by dad & 0.96 & $0.93,0.99$ & 0.98 & $0.95,1.03$ \\
\hline Parental cigarette use & 1.22 & $0.96,1.54$ & 1.29 & $0.99,1.67$ \\
\hline Parental alcohol use & 0.98 & $0.73,1.32$ & 0.86 & $0.62,1.18$ \\
\hline Parental marijuana use & 1.09 & $0.85,1.38$ & 0.94 & $0.74,1.19$ \\
\hline \multicolumn{5}{|l|}{ Control variables } \\
\hline Age & 0.98 & $0.79,1.23$ & 0.99 & $0.8 \mathrm{I}, \mathrm{I} .20$ \\
\hline Gender (ref. = M) & 1.23 & $0.73,2.06$ & 1.07 & $0.65,1.77$ \\
\hline SES & 0.99 & $0.95,1.04$ & 0.99 & $0.96,1.04$ \\
\hline Number of peers who use cigarettes & 1.24 & $0.95,1.62$ & 1.19 & $0.89,1.59$ \\
\hline Number of peers who use alcohol & 1.08 & $0.85,1.37$ & 0.53 & $0.39,0.75$ \\
\hline Number of peers who use marijuana & 1.47 & $1.22,1.78$ & 1.89 & $1.45,2.45$ \\
\hline Peer pressure to smoke & 1.21 & $0.83,1.78$ & 0.98 & $0.63,1.54$ \\
\hline Peer pressure to drink & 1.38 & $0.92,2.10$ & 1.79 & $1.08,2.99$ \\
\hline Peer pressure to use marijuana & 1.57 & $1.07,2.30$ & 0.78 & $0.47,1.30$ \\
\hline Youth autonomy & 0.99 & $0.95,1.03$ & 1.06 & $1.01,1.14$ \\
\hline
\end{tabular}

Notes: For ease of interpretation, we have used bold text to highlight statistically significant findings. Likelihood ratio test of alpha $=0: \bar{x}^{2}=44.42, P<0.00$.

Abbreviations: SES, socioeconomic status; $\mathrm{Cl}$, confidence interval.

Chilean adolescents ever used marijuana was the adolescents' certainty that their parents had used marijuana. Despite the number of family factors preventing adolescents from using marijuana and the number of studies pointing to the influence of peers over family, ${ }^{61}$ perception of marijuana use within the family serves an important socializing role for our sample of Chilean adolescents. This finding is consistent with existing research on the transmission of drug use through parental introduction and socialization into drug use. ${ }^{21,62,63}$ Considering the continuing increase in illicit drug consumption among youth in Latin America, this finding is particularly troublesome as it indicates that the transmission of drug use within Chilean families will surely influence drug use in future generations. Research is needed to strengthen interventions that may serve to interrupt the intergenerational transmission of drug use from parents to their children.

Regarding the marijuana-related problems that adolescents reported, we found that higher perceptions of family involvement, parental monitoring, and warm parenting by fathers were protective factors in bivariate models. However, in the multivariate model, none of these protective factors remained significant in reducing the number of problems that adolescents experience as a result of using marijuana. Although not significant at the bivariate level, perhaps as a result of a suppression effect, harsh parenting by fathers was associated with a higher number of adolescent reports of marijuana-related problems. To understand this association we consider 2 possible pathways from parenting behaviors to child substance use outcomes. First, it is possible that harsh parenting increases adolescent aggression and rule breaking, a finding which is well supported cross-culturally in the research literature (eg, Gershoff et $\mathrm{al}^{64}$ ). Such rule breaking behavior may bring the adolescent into peer contexts that provide increased opportunities to use marijuana. Alternatively, it is possible that increased harsh parenting is associated with increases in internalizing behavior problems and that adolescents attempt to ameliorate these internalizing behavior problems through marijuana consumption. Fathers' use of harsh discipline as the only variable in the multivariate models to be associated with marijuana-related problems has some support in the literature. Subsequent research should seek to understand whether this association between harsh parenting and marijuana-related problems is found in other Latin American samples. Due to the cross-sectional nature of this study, future research would also benefit by seeking to understand the precise nature of the mechanism connecting harsh parenting and marijuana problems, to determine whether harsh discipline or adolescent marijuana 
use develops first. At a minimum, longitudinal data and sophisticated analytic strategies will need to be employed to begin to find answers to these questions. It is possible that parents of adolescents who use marijuana might be experiencing greater levels of stress and less satisfaction with parenting as a result of having to parent an adolescent who is involved in risky behavior. ${ }^{65}$

The study findings need to be interpreted within the context of four limitations. First, this study analyzed cross-sectional data, preventing us from making statements about causal and temporal inferences for some of the variables. The behavior of family and parents may in fact be responsive to how adolescents behave. In fact, the results of the final multivariate models indicate that many of the variables representing peer effects retained their statistical significance while many of the family characteristics were no longer statistically significant. It may be that youth involvement with peers mediates the connection between family characteristics and marijuana usage or problems with marijuana. At a minimum, longitudinal data will be needed to make stronger inferences about the nature of the family, peer, and youth marijuana use relationships examined in this study. ${ }^{66,67}$ Second, all information in this study is based on adolescent self-reports, the exception being the SES data. Such perceived information by adolescents reflects only their perceptions and certainty of family, parents, and peer behaviors. If anything, the associations identified may be underestimating the true nature of the relationships studied. Future research would benefit from using data collected from multiple informants such as parents, peers, other adults, and teachers. Third, the overall small number of youth who endorsed lifetime use of marijuana and who reported marijuana-related problems resulted in diminished statistical power. Similar studies with larger samples are needed to examine if these findings can be replicated. Finally, more work is needed to establish the cross-cultural validity of the parenting measures used in the present study in order to avoid the type of pitfalls associated in administering assessments across cultures described by other researchers. ${ }^{68}$

Notwithstanding these limitations, the research findings from this study are generally consistent with previous studies that identify the associations of marijuana-consuming behavior of adolescents across the three dimensions of youth, parents, and peers. An important strength of this study is that multiple dimensions of parenting and family life were explored and contributed to a richer contextual understanding of adolescent substance use. Increasingly, research on families and parenting is recognizing the importance of including multiple dimensions of parenting. ${ }^{64}$ Focusing on this broader set of family and parenting behaviors allows for the identification of more precise relationships between specific dimensions of family and parenting with marijuana use outcomes.

There are several implications of this study's findings for the development of possible prevention interventions. First, findings indicate that interventions aimed at decreasing harsh parenting behavior may, among other benefits, result in decreased marijuana usage. It is also possible that programs which work with both parents and adolescents together in efforts aimed at preventing the onset of marijuana use may be succesful. Further, given the finding that parental marijuana use is associated with adolescent use, a necessary topic of discussion during these interventions should be parents' own marijuana use. A related suggestion for intervention efforts would be to have programs available for the parents to reduce their own consumption. The findings of this study also have implications for more targeted interventions. In terms of how to decrease problems related to the use of marijuana among adolescent marijuana users, and given the finding that harsh parenting by fathers is a risk factor, fathers should be included as part of the intervention, and provided with assistance on how to manage stress to eventually decrease harsh parenting practices. Focusing on strengthening parenting by fathers might not directly decrease adolescent substance use, but might indirectly achieve this by reducing familial stress and improve coping.

In this paper we have shown that a host of family and parenting behaviors, as reported by the adolescents themselves, influence Chilean adolescent use of marijuana, and the problems they experience as a result of using this drug. Because many of these findings are consistent with research findings from US and European samples, we can suggest that there is at least some support for the idea that universal commonalities may exist between the protective and promotive effects of parenting behaviors for adolescent substance use, across cultures. Future research on the relationship between parenting and family factors, and adolescent substance use, is needed across a wide variety of cultural contexts.

\section{Acknowledgments}

We are extremely grateful to the adolescents of the Santiago Longitudinal Study and their families for taking the time to participate in this study. This research was funded by NIDA Grant \# RO1 DA021181 and the Curtis Research and Training Center at the University of Michigan School of Social Work.

\section{Disclosure}

The authors disclose no conflicts of interest. 


\section{References}

1. United Nations. World Drug Report 2009. http://www.unodc.org/ unodc/en/data-and-analysis/WDR-2009.html. Accessed March 29, 2010 .

2. United Nations Office on Drugs and Crime. Youth and drugs in South American countries: A public policy challenge. 2006. http://www.cicad. oas.org/OID/NEW/Statistics/siduc/Executive-summary-secondarystudents.pdf. Accessed March 29, 2010.

3. United Nations Office on Drugs and Crime. Subregional System of Information and Research on Drugs in Argentina, Chile, Bolivia, Ecuador, Peru, and Uruguay: First Comparative Study on Druge Use and Associated Factors in the General Population 15-64 years of age. 2008. http://www.cicad.oas.org/OID/NEW/Research/Executive Summary-2008subregional.pdf. Accessed March 29, 2010.

4. REDLA Network Identifies Worrisome Trends in Drug Use across Latin America. 2008. http://www.cicad.oas.org/oid/NEW/Information/ Observer/08_01/REDLA.asp. Accessed December 4, 2009.

5. Informe subregional sobre uso de drogas en pobacion escolarizada: United Nations on Drugs and Crime and the Inter-American Observatory on Drugs Inter-American Drug Abuse Control Commission; 2010.

6. Ennett ST, Foshee VA, Bauman KE, et al. The social ecology of adolescent alcohol misuse. Child Dev. 2008;79(6):1777-1791.

7. Szapocznik J, Prado G, Burlew AK, Williams RA, Santisteban DA. Drug abuse in African American and Hispanic adolescents: culture, development, and behavior. Annu Rev Clin Psychol. 2007;3: 77-105.

8. Springer A, Parcel G, Baumler E, Ross M. Supportive social relationships and adolescent health risk behavior among secondary school students in El Salvador. Soc Sci Med. 2006;62(7):1628-1640.

9. Santander S, Zubarew T, Santelices L, Argollo P, Cerda J, Borquez M. Influencia de la familia como factor protector de conductas de riesgo en escolares chilenos [Family influence as a protective factor against risk behaviors in Chilean adolescents]. Revista médica de Chile. 2008; 136:317-324.

10. Rees R, Valenzuela A. Características individuales y de la estructura familiar de un grupo de adolescentes abusadores de alcohol y/o marihuana [Individual and family structure characteristics of a group of adolescents abusers of alcohol and/or cannabis]. Revista Chilena de Neuro-Psyquiatria. 2003;41(3):173-185.

11. Williams J, Smith J. Alcohol and other drug use among adolescents: family and peer influences. J Subst Abuse. 1993;5(3):288-294.

12. Adlaf EM, Ivis FJ. Structure and relations: The influence of familial factors on adolescent substance use and delinquency. J Child Adolesc Subst Abus. 1996;5(3):1-19.

13. Ary DV, Duncan TE, Biglan A, Metzler CW, Noell JW, Smolkowski K. Development of adolescent problem behavior. J Abnorm Child Psychol. 1999;27(2):141.

14. Caldwell RM, Sturges SM, Silver NC, Brinson J, Denby-Brinson R, Burgess K. An examination of the influence of perceived parenting practices on depression and substance use among African American juvenile offenders. J Forensic Psychol Pract. 2006;6(3):31-50.

15. Hoffmann JP. The effects of family-structure and family-relations on adolescent marijuana use. Int J Addict. 1995;30(10):1207-1241.

16. Dishion T, Loeber R. Adolescent marijuana and alcohol use: The role of parents and peers revisited. Am J Drug Alcohol Abuse. 1985;11(1):11-25.

17. Latendresse SJ, Rose RJ, Viken RJ, Pulkkinen L, Kaprio J, Dick DM. Parenting mechanisms in links between parents' and adolescents' alcohol use behaviors. Alcohol Clin Exp Res. 2008;32(2): 322-330.

18. Parker J. Parent-adolescent relations and adolescent functioning: self-Esteem, substance abuse, and delinquency. Adolescence. 2004;39(155):519-530.

19. Pettit GS, Laird RD, Dodge KA, Bates JE, Criss MM. Antecedents and behavior-problem outcomes of parental monitoring and psychological control in early adolescence. Child Dev. 2001;72(2):583-598.
20. Chilcoat HD, Anthony JC. Impact of parent monitoring on initiation of drug use through late childhood. J Am Acad Child Adolesc Psychiatry. 1996;35(1):91-100.

21. Benjet C, Borges G, Medina-Mora ME, et al. Drug use opportunities and the transition to drug use among adolescents from the Mexico City Metropolitan Area. Drug Alcohol Depend. 2007;90(2):128-134.

22. Arria AM, Kuhn V, Caldeira KM, O'Grady KE, Vincent KB, Wish ED. High school drinking mediates the relationship between parental monitoring and college drinking: a longitudinal analysis. Subst Abuse Treat Prev Policy. 2008;3:11.

23. Wagner KD, Ritt-Olson A, Chou C-P, et al. Associations between family structure, family functioning, and substance use among Hispanic/Latino adolescents. Psychol Addict Behav. 2010;24(1):98-108.

24. Yabiku ST, Marsiglia FF, Kulis S, Parsai MB, Becerra D, Del-Colle M. Parental monitoring and changes in substance use among Latino/a and non-Latino/a preadolescents in the southwest. Subst Use Misuse. 2010;45(14):2524-2550.

25. Chen C, Storr C, Anthony J. Influences of parenting practices on the risk of having a chance to try cannabis. Pediatrics. 2005; 115(6):1631-1639.

26. Reboussin BA, Hubbard S, Ialongo NS. Marijuana use patterns among African-American middle-school students: a longitudinal latent class regression analysis. Drug Alcohol Depend. 2007;90(1):12-24.

27. Mrug S, Gaines J, Su W, Windle M. School-level substance use: effects on early adolescents' alcohol, tobacco, and marijuana use (Report). J Stud Alcohol Drugs. 2010;71(4):488.

28. Mogro-Wilson C. The influence of parental warmth and control on Latino adolescent alcohol use. Hisp J Behav Sci. 2007;30(1): 89-105.

29. Chassin L, Presson CC, Rose J, Sherman SJ, Davis MJ, Gonzalez JL. Parenting style and smoking-specific parenting practices as predictors of adolescent smoking onset. J Pediatr Psychol. 2005 Jun;30(4): 333-344.

30. Kliewer W, Murrelle L. Risk and protective factors for adolescent substance use: Findings from a study in selected Central American countries. J Adolesc Health. 2007;40(5):448-455.

31. Stice E, Barrera M, Chassin L. Relation of parental support and control to adolescents' externalizing symptomatology and substance use: A longitudinal examination of curvilinear effects. J Abnorm Child Psychol. 1993;21(6):609-629.

32. Barnes GM, Farrell MP. Parental Support and Control as Predictors of Adolescent Drinking, Delinquency, and Related Problem Behaviors. J Marriage Family. 1992;54(4):763-776.

33. Bandura A. Social learning theory. Oxford England: Prentice-Hall; 1977.

34. De Micheli D, Formigoni M. Are reasons for the first use of drugs and family circumstances predictors of future use patterns? Addict Behav. 2002;27(1):87-100.

35. Andrews JA, Hops H, Ary D, Tildesley E, Harris J. Parental Influence on Early Adolescent Substance Use: Specific and Nonspecific Effects. J Early Adolesc. 1993;13(3):285-310.

36. Andrews JA, Hops H, Duncan SC. Adolescent modeling of parent substance use: the moderating effect of the relationship with the parent. J Fam Psychol. 1997;11(3):259-270.

37. Foley JD. Adolescent use and misuse of marijuana. Adolesc Med Clin. 2006; 17:319-334.

38. Gfroerer J. Correlation between drug use by teenagers and drug use by older family members. Am J Drug Alcohol Abuse. 1987;13(1-2):95-108.

39. Merikangas KR. Familial transmission of substance use disorders. Arch Gen Psychiatry. 1998;55(11):973-979.

40. Caris L, Anthony CB, Rios-Bedova CF, Anthony JC. Behavioral problems and the occurrence of tobacco, canabis, and coca paste smoking in Chile: Evidence based on multivariate response models for school survey data. Drug Alcohol Depend. 2009;104:50-55.

41. Caris L, Wagner FA, Rios-Bedova CF, Anthony JC. Opportunities to use drugs and stages of drug involvement outside the United States: Evidence from the Republic of Chile. Drug Alcohol Depend. 2009; 102:30-34. 
42. Caris L, Varas M, Anthony CB, Anthony JC. Behavioral problems and tobacco use among adolescents in Chile. Rev Panam Salud Publica. 2003;14:84-89.

43. Fuentealba R, Cumsille F, Araneda JC, Molina C. Consumption of licit and illicit drugs in Chile: results of the 1998 study and comparison with the 1994 and 1996 studies. Rev Panam Salud Publica. 2000;7: 79-87.

44. Martinez-Aguayo A, Araneda JC, Fernandez D, Gleisner A, Perez V, Codner E. Tobacco, alcohol, and illicit drug use in adolescents with diabetes mellitus. Pediatr Diabetes. 2007;8:265-271.

45. Rodriguez J, Hernandez E, Fernandez M. Descripcion del consumo de drogas licitas e ilicitas por genero a traves de la metodologia de pares (A gender comparison of legal and illicit drug consumption). Revista medica de Chile. 2007;135:449-456.

46. Araneda JC, Cumsille F. Consumo de drogas en población escolar de Chile en alumnos de $8^{\circ}$ básico a $4^{\circ}$ medio, 2003. Revista Chilena de Salud Publica. 2004;8(2):63-71.

47. Lozoff B, de Andraca I, Castillo M, Smith JB, Walter T, Pino P. Behavioral and developmental effects of preventing iron-deficiency anemia in healthy full-term infants. Pediatrics. 2003;112(4):846-849.

48. Johnston LD, O’Malley PM, Bachman JG, Schulenberg J. Volume I: Secondary school students. Bethesda, MD: (NIH Publication No. 09-7402) National Institute on Drug Abuse; 2009.

49. Alonso J, Urzola D, Serra-Sutton V, et al. Validity of the health profiletypes of the Spanish Child Health and Illness Profile-Adolescent Edition (CHIP-AE). Value Health. 2008;11(3):440-449.

50. Riley AWP, Green BFP, Forrest CBMDP, Starfield BMDMPH, Kang MMHS, Ensminger MEP. A taxonomy of adolescent health: development of the adolescent health profile-types. Medical Care. 1998;36(8):1228-1236.

51. Riley AW, Forrest C, Starfield B, Green B, Kang M, Ensminger M. Reliability and validity of the adolescent health profile-types. Medical Care. 1998;36(8):1237-1248.

52. NCHHD. National Institute of Child Health and Human Development Study of early Child Care and Youth Development: Phase IV Instrument DocumentationBethesda: NIH; 2008.

53. Melby JN, Conger RD. The Iowa Family Interaction Rating Scales: Instrument Summary. Family observational coding systems: Resources for systemic research. Mahwah, NJ: Lawrence Erlbaum Associates 2001:33-58.

54. Conger RD, Ge X. Conflict and cohesion in parent-adolescent relations: Changes in emotional expression from early to mid-adolescence. In: Cox MJ, Brooks-Gunn J, editors. Conflict and cohesion in families. Causes and consequences. Mahwah, NJ: Erlbaum; 1999:185-206.
55. Conger RD, Ge X, Elder GH, Lorenz FO, Simons RL. Economic stress, coercive family process, and developmental problems of adolescents. Child Dev. 1994;65(2):541-561.

56. Eccles J, Buchanan C, Flanagan C, Fuligni A, Midgley C, Yee D. Control versus autonomy during early adolescence. Journal of Social Issues. 1991;47(4):53-68.

57. Brody G, Moore K, Glei D. Family processes during adolescence as predictors of parent young-adult attitude similarity: A 6-year longitudinal analysis. Family Relations. 1994;43(4):369-373.

58. Graffar M. Une methode de clasificacion sociale d'echantillons de population. Courier. 1956;6(8):455-459.

59. StataCorp. Stata Statistical Software: Release 11.1. College Station, TX: StataCorp, LP; 2009.

60. Brook J, Brook D, Kats N, Arencibia-Mireles O, Finch S. Ecology and drug use: Universal predictors across time and place. Psychol Rep. 2009;104(3):989-1006.

61. Lopez B, Wang W, Schwartz SJ, et al. School, family, and peer factors and their association with substance use in Hispanic adolescents. J Prim Prev. 2009;30(6):622-641.

62. Gfroerer J, de la Rosa M. Protective and risk factors associated with drug use among Hispanic youth. J Addict Dis. 1993;12(2):87-107.

63. Richardson MA, Newcomb MD, Myers HF, Coombs RH. Psychosocial predictors of recent drug use among Anglo and Hispanic children and adolescents. J Child Adolesc Subst Abus. 2002;12(2):47-76.

64. Gershoff ET, Grogan-Kaylor A, Lansford JE, et al. Parent discipline practices in an international sample: associations with child behaviors and moderation by perceived normativeness. Child Dev. 2010;81(2):487-502.

65. Sanders MR, Dittman CK, Keown LJ, Farruggia S, Rose D. What are the parenting experiences of fathers? The use of household survey data to inform decisions about the delivery of evidence-based parenting interventions to fathers. Child Psychiatry Hum Dev. 2010;41(5): $562-581$.

66. Delva J, Grogan-Kaylor A, Andrade F, Hynes M, Sanchez N, Bares C. An agenda for Longitudinal Research on Substance Use and Abuse with Hispanics in the US and with Latin American Populations. In: Thomas YF, Price LN, Lybrand AV, editors. Drug Use Trajectories among African American and Hispanic Youth: Springer Pubs; Forthcoming 2010.

67. Grogan-Kaylor A. Relationship of corporal punishment and antisocial behavior by neighborhood. Arch Pediatr Adolesc Med. 2005;159(10):938-942.

68. Vandevijver F. Bias and equivalence in cross-cultural assessment: an overview. Eur Rev Applied Psychol. 2004;54(2):119-135.

Substance Abuse and Rehabilitation

\section{Publish your work in this journal}

Substance Abuse and Rehabilitation is an international, peer-reviewed, open access journal publishing original research, case reports, editorials, reviews and commentaries on all areas of addiction and substance abuse and options for treatment and rehabilitation. The manuscript management system is completely online and includes a very quick and

fair peer-review system. Visit http://www.dovepress.com/testimonials. php to read real quotes from published authors. 